\title{
PARÂMETROS DE QUALIDADE DE ÁGUA DE RIOS E EFLUENTES PRESENTES EM MONITORAMENTOS NÃO SISTEMÁTICOS
}

\author{
QUALITY WATER PAREMETERS OF RIVERS AND \\ WASTEWATER PRESENT IN NO SYSTEMATIC \\ MONITORING
}

Rubia Girardi ${ }^{1}$, Adilson Pinheiro' ${ }^{1}$ Pedro Thiago Venzon ${ }^{1}$

${ }^{1}$ Fundação Universidade Regional de Blumenau - FURB, Blumenau, SC, Brasil. E-mails: ru.girardi@gmail.com, pinheiro@furb.br, pedro.thiago@hotmail.com

Como citar: Girardi, R.; Pinheiro, A.; Venzon, P. T. Parâmetros de qualidade de água de rios e efluentes presentes em monitoramentos não sistemáticos. Revista de Gestão de Água da América Latina, v. 16, e2, 2019. 10.21168/rega.v16e2.

\begin{abstract}
RESUM0: Nas últimas décadas, tem sido consenso que as atividades humanas degradam a qualidade das águas superficiais e subterrâneas. 0 Brasil possui problemas de escassez de dados de qualidade da água. 0 presente trabalho possui o intuito de analisar os parâmetros utilizados nos monitoramentos não sistemático da qualidade da água de rios e efluentes na Bacia Hidrográfica do Rio Itajaí (BHRI). A partir destes dados, foi possível verificar os parâmetros mais frequentes e confrontar os mesmos com a legislação vigente. Foram avaliados 4947 laudos de 216 empresas, totalizando 250 parâmetros. Dos parâmetros solicitados pelos órgãos ambientais e que não constam nas legislações, destacaram-se pela quantidade de análises realizadas a demanda química de oxigênio (DQO), sólidos sedimentáveis, cor aparente, nitrogênio Kjedahl, coliformes totais e ferro total. Constatou-se a falta de informação sobre a vazão de lançamento dos efluentes, assim como, da qualidade da água dos corpos receptores após a zona de mistura. Percebeuse a necessidade de realinhamento dos procedimentos operacionais dentro dos órgãos de fiscalização, alinhando a exigência dos parâmetros com a legislação vigente. Além de aprimorar a uniformidade entre os parâmetros e periodicidade requerida das empresas. Em relação à normatização, os laboratórios também precisam adotar metodologias padronizadas de monitoramento e métodos de análise.
\end{abstract}

Palavras-chave: Gestão integrada de recursos hídricos, legislação ambiental, CONAMA 357, CONAMA 430, poluição hídrica.

ABSTRACT: In the last decades, there is an agreement that the human activities degrade the superficial and underground quality water. Brazil has problems with water quality shortage data in some regions. This work analyzes which parameters are monitored of water quality in rivers and wastewater in the Rio Itajaí Watershed. With this information, we discovered the most frequently parameters and confront with current legislation. We evaluated 4947 reports of 216 companies, totalizing 250 parameters. Into the parameters requested to the environmental organization and are not in the legislation, highlighting to be COD, settleable solids, apparent color, Kjedahl nitrogen, total coliform, and total iron. We constated lack of data about wastewater flow, as soon as, the courses water quality after mixing zone. We detected the necessity to standardization operational procedure inside of government organisms, lining the parameters solicited with legislation. Moreover, it is important improves the uniformity of parameters and periodicity between corporations. About uniformization, the laboratories need adopt standard methodology, especially to monitoring and analysis.

Keywords: Integrated Water Resources Management (IWRM), environmental legislation, CONAMA 357, CONAMA 430, hydric pollution. 


\section{INTRODUÇÃO}

A demanda mundial de água doce tem aumentado a um ritmo anual aproximado de $1 \%$ ao ano, ocorrendo em função do aumento da população, desenvolvimento econômico e alterações nos padrões de consumo. A tendência é continuar ocorrendo aumento na demanda industrial e doméstica, mas o setor agrícola segue sendo o principal consumidor mundial de água. A maior demanda de água deverá ocorrer em economias emergentes ou em desenvolvimento, como é o caso do Brasil (PROGRAMA MUNDIAL DE LAS NACIONES UNIDAS DE EVALUACIÓN DE LOS RECURSOS HÍDRICOS, 2018).

A partir da década de 1990, a alteração das características das águas piorou a qualidade de quase todos os corpos de água da América Latina, África e Ásia. A qualidade da água possui uma tendência de piorar nas próximas décadas, ameaçando a saúde humana, o meio ambiente e o desenvolvimento sustentável. Em nível mundial, o desafio mais frequente é a carga de nutrientes, que dependendo da região se associa com a de patógenos (PROGRAMA MUNDIAL DE LAS NACIONES UNIDAS DE EVALUACIÓN DE LOS RECURSOS HÍDRICOS, 2018).

A qualidade da água superficial está relacionada à condicionantes naturais como regime de chuvas, geologia, escoamento superficial, cobertura florestal. Assim como as condicionantes antrópicas como lançamento de efluentes, tanto de fontes pontuais como difusas, manejo do solo, entre outros (AGÊNCIA NACIONAL DE ÁGUAS, 2017; PIAZZA et al., 2018).

De acordo com Pessôa (2013), fontes de poluição pontuais são características por terem origem identificável, sendo possível o controle da qualidade, frequência e quantidade do efluente no lançamento, enquanto as fontes difusas, não tem ponto de lançamentos e frequência definidas, dificultando assim o seu controle. Poluentes de origem difusa chegam aos cursos da água pelo escoamento superficial, gerado em eventos de chuvas intensas e/ou prolongadas. Por isso que, nos períodos chuvosos, especialmente nas primeiras chuvas, há grande contribuição de poluição difusa nos corpos de água (COELHO et al., 2017). Como fontes de poluição de origem difusa pode-se descrever indústrias, que lançam seu efluente na rede coletora pluvial ou de esgoto, dificultando a identificação do local e da origem dos poluentes, assim como atividade agrícola e esgotamento sanitário, especialmente as ligações clandestinas.

0 monitoramento ambiental de longo prazo possibilita o conhecimento de tendências de evolução da qualidade, viabilizando o diagnóstico do corpo de água (PIAZZA et al., 2018). Com o intuito de traçar os planos de ação, para implementar a governança dos recursos hídricos, é necessário saber a qualidade atual e o uso previsto para as águas, para que se possa estabelecer os requisitos necessários de melhoria. 0 enquadramento é um dos instrumentos da Política Nacional de Recursos Hídricos (PNRH) para assegurar qualidade dos recursos hídricos adequada aos diferentes usos. É utilizada como referência a Resolução do CONAMA no 357 (BRASIL, 2005) para classificação dos corpos de águas superficiais. Como a classificação se dá por meio dos parâmetros de qualidade, é de grande importância o monitoramento dos corpos de água. A implantação de uma rede nacional de monitoramento da qualidade da água é um grande desafio no Brasil, por se tratar de um país com grandes dimensões. Além da questão da heterogeneidade das redes existentes nas unidades da federação (UF), essas redes não possuem padronização nos parâmetros analisados, assim como na frequência das coletas (QUALIAGUA, 2018). O monitoramento necessita grande número de equipamentos, além de profissionais habilitados, resultando em um processo com alto custo financeiro. Há no Brasil uma rede de qualidade de água operada pela Agência Nacional de Águas (ANA), que em 2016 contava com 1652 pontos, onde são realizadas análises básicas como pH, oxigênio dissolvido, condutividade elétrica e temperatura (AGÊNCIA NACIONAL DE ÁGUAS, 2017).

Para contornar a situação de escassez de dados em algumas regiões do país, além das diferenças quanto à capacidade operacional, divulgação e disponibilização dos resultados do monitoramento entre as Unidades da Federação (UF), a ANA iniciou algumas ações com o objetivo de solucionar esses problemas; tais como Programa Nacional de Avaliação da Qualidade das Águas (PNQA), a Rede Nacional de Monitoramento da Qualidade de Água (RNQA) e o Programa de Estímulo à Divulgação de Dados de Qualidade de Água (Qualiágua). 0 Qualiágua, lançado pela ANA em 2014, incorpora o PNQA, o RNQA, padronização, laboratórios e capacitação e avaliação, visando uma gestão mais sistemática dos recursos hídricos (AGÊNCIA NACIONAL DE ÁGUAS, 2017). No entanto, essa rede ainda não está consolidada. Há ainda o desafio de alcançar o diagnóstico da qualidade dos corpos de água em vários estados da federação, como em Santa Catarina, primordial para os planos de bacias e enquadramento, ambos instrumentos da PNRH. Atualmente o Qualiágua está em fase de implantação no estado catarinense. 
Ações de automonitoramento da qualidade da água dos rios e efluentes são realizadas por empresas e entidades públicas. Essas ações são exigidas pelos diferentes órgãos de fiscalização e controle como Vigilância Sanitária, ANA/ANEEL, e no Estado de Santa Catarina pelo Instituto do Meio Ambiente (IMA/SC) e Diretoria de Recursos Hídricos (DIRH). Adicionalmente, monitoramentos pontuais são executados pela Polícia Ambiental de SC.

As ações de automonitoramento geram diversos laudos com parâmetros e periodicidade distintos. Isso ocorre pela ausência de normativas internas dentro de alguns órgãos, assim como, legislações distintas dependendo da área de atuação de cada entidade. Atividades potencialmente poluidoras estão sujeitas às resoluções CONAMA 357/2005 e 430/2011. Além disso, no Estado de Santa Catarina essas empresas estão sujeitas ao Código Ambiental de Santa Catarina, Lei Estadual 14675/2009. A Resolução no 001/2008 do Conselho Estadual de Recursos Hídricos (CONSELHO ESTADUAL DE RECURSOS HÍDRICOS, 2018) de Santa Catarina, resolve pela adoção da Resolução CONAMA no357/2005 para o enquadramento, enquanto não é aprovado o novo enquadramento dos corpos d'água superficiais do estado. Essa análise estabelece limites aos parâmetros químicos, físicos e biológicos, de acordo com cada uso previsto.

A Resolução CONAMA no 357/2005 classifica os corpos de água em: doce, salgada e salobra. Os corpos hídricos de água doce são classificados em cinco categorias. A classe especial é a que possui melhor qualidade da água e usos mais restritivos. Em ordem decrescente de qualidade da água, há as classes 1, 2, 3 até a 4. As águas salobras possuem salinidade entre 0,5 a 30\%o, e é dividida em quatro categorias, com a melhor qualidade para a classe especial e a pior para a classe 3 . As águas salinas possuem salinidade igual ou superior a 30\%o e também são divididas em quatro classes, da mesma forma que as salobras. Quando um corpo hídrico for enquadrado como classe especial, deverão ser mantidas as condições naturais. Enquanto que as demais classes possuem seus padrões e condições que devem ser atendidos (BRASIL, 2005; AGÊNCIA NACIONAL DE ÁGUAS, 2013).

Em relação à água doce, além das condicionantes básicas para qualidade da água, há também parâmetros específicos com seus valores limites. A água doce classe 1 e 2 utiliza a mesma listagem de parâmetros, apresentando uma lista extra para água que é utilizada para pesca ou cultivo de organismos para fins de consumo intensivo. A classe doce 3 possui uma tabela própria de padrões e seus limites, possuindo valores máximos mais flexíveis. A água doce 4 observa apenas algumas condições e padrões (BRASIL, 2005).

As águas salobras de classe 1 precisam obedecer algumas condições e padrões mais elementares. Além disso, há uma tabela de parâmetros inorgânicos e orgânicos com valores máximos permitidos. Sendo que as águas salobras destinadas a pesca ou cultivo de organismos para fins de consumo intensivo possuem restrição maior para arsênio total e alguns parâmetros orgânicos. As águas salobras de classe 2 possuem condições mais flexíveis e uma tabela própria com menor variedade de padrões a serem controlados. A classe 3 é a menos restritiva (BRASIL, 2005).

A Resolução CONAMA no 430/2011 dispõe sobre "as condições e padrões de lançamento de efluentes, complementa e altera a Resolução CONAMA no 357/2005”. Esta Resolução destaca que "os efluentes não poderão conferir ao corpo receptor características de qualidade em desacordo com as metas obrigatórias progressivas, intermediárias e final, do seu enquadramento".

Para o lançamento direto nos corpos receptores, os efluentes de qualquer fonte poluidora deverão possuir pH entre 5 e 9 , temperatura inferior a $40{ }^{\circ} \mathrm{C}$, materiais sedimentáveis até $1 \mathrm{~mL} / \mathrm{L}$, óleos minerais até $20 \mathrm{mg} / \mathrm{L}$, óleos vegetais e gorduras animais até $50 \mathrm{mg} / \mathrm{L}$, ausência de materiais flutuantes e DBO com remoção mínima de 60\%. Adicionalmente, há 21 parâmetros inorgânicos, destes 14 são metais; e ainda 10 parâmetros orgânicos, sendo 5 destes compostos aromáticos (BRASIL, 2011a).

Para os efluentes de sistemas de tratamento de esgoto sanitário, é mantida a mesma condição para $\mathrm{pH}$, temperatura, materiais sedimentáveis e flutuantes. No entanto, é estabelecido o limite de $120 \mathrm{mg} / \mathrm{L}$ para a DBO, ou tratamento com eficiência de remoção mínima de $60 \%$. Adicionalmente, as substâncias solúveis em hexano como óleos e graxas podem atingir o limite de $100 \mathrm{mg} / \mathrm{L}$. Também poderão ser exigidos, a critério do órgão ambiental, 21 parâmetros inorgânicos, exceto nitrogênio amoniacal total e os 10 orgânicos. "Os efluentes de sistemas de tratamento de esgotos sanitários poderão ser objeto de teste de ecotoxicidade no caso de interferência de efluentes com características potencialmente tóxicas ao corpo receptor. " Para os efluentes oriundos de serviços de saúde, além da mesma exigência do esgotamento sanitário, ainda estão sujeitas às normas sanitárias específicas (BRASIL, 2011a).

A Portaria de Consolidação no 5 de 28 de setembro de 2017, revogou a Portaria MS no 2914/2011 (BRASIL, 2011b). No entanto, apesar da Portaria não estar mais vigente, seu conteúdo está e 
apresenta-se inserido na Portaria de Consolidação no 5 (BRASIL, 2017). Na Portaria de Consolidação MS 5/2017, capítulo VI, art. 40, descreve que o controle da qualidade da água para consumo humano, supridos por manancial superficial e subterrâneo, devem coletar amostras semestrais da água bruta, no ponto de captação. Os parâmetros exigidos para estas análises devem estar de acordo com legislações específicas. No caso da água superficial, seriam as Resoluções CONAMA no 357/2005 e CONAMA no 430/2011, citadas anteriormente.

O Código Ambiental de Santa Catarina (CONSELHo ESTADUAL DO MEIO AMBIENTE, 2009) apresenta as competências de órgãos ambientais estaduais. Além disso, estabelece em seu Art. 177, condições para lançamentos de efluentes em corpos de água interiores, lagunas, estuários e na beiramar. Estabelecendo limites para os parâmetros:

"pH; materiais flutuantes visíveis; óleos vegetais e gorduras animais; cromo hexavalente; cobre total; cádmio total; mercúrio total; níquel total; zinco total; arsênio total; prata total; selênio total; manganês+2 solúvel; fenóis; substâncias tensoativas que reagem ao azul de metileno; compostos organofosforados e carbamatos; compostos organofosforados e carbamatos; sulfeto de carbono, etileno; outros compostos organoclorados (CONSELHO ESTADUAL DO MEIO AMBIENTE, 2009)"

Destes parâmetros, pH, DBO, óleos vegetais e gorduras animais, cobre total, cádmio total, mercúrio total, níquel total, zinco total, arsênio total, prata total, selênio total e sulfeto de carbono apresentam limites de lançamento inferiores à Resolução CONAMA 430/2011. O fenol, as substâncias tensoativas que reagem ao azul de metileno, os compostos organofosforados e carbamatos e outros compostos organoclorados não estão previstos na Resolução CONAMA 430/2011. A Lei Estadual 14675/2009 também estabelece limite para o parâmetro fósforo total, $4 \mathrm{mg} / \mathrm{L}$, para lançamentos em trechos de lagoas, lagunas e estuários.

Em função do baixo nível de informação de qualidade de água dos corpos hídricos superficiais brasileiros, buscam-se alternativas para o resgate de informação destes dados. Desta forma, o presente trabalho possui o intuito de analisar qualitativamente quais os parâmetros monitorados da qualidade da água dos rios e efluentes lançados na região da Bacia Hidrográfica do Rio Itajaí (BHRI), maior bacia hidrográfica do estado de Santa Catarina. Estes monitoramentos não são sistemáticos, sendo realizados por entidades públicas e ou privadas e exigidos por diferentes órgãos de regulamentação e fiscalização.

\section{MATERIAIS E MÉTODO}

Este trabalho tem por finalidade compreender o tipo de informação gerada nos automonitoramentos da qualidade da água superficial realizados por diferentes entidades pertencentes à Bacia Hidrográfica do Rio Itajaí (BHRI). A BHRI é a maior vertente do litoral de Santa Catarina com aproximadamente $15000 \mathrm{Km}^{2}$, sendo a maior bacia hidrográfica estadual. Está distribuída em 53 municípios, destes 47 possuem sua sede dentro da bacia, sendo Blumenau, o principal polo econômico da região (COMITÊ DO ITAJAÍ, 2010; SANTA CATARINA, 2017). Após a confluência do Rio Itajaí do Oeste com o Itajaí do Sul, é formado o Rio Itajaí-Açu, onde são encontrados os maiores focos de poluição, especialmente após drenar centros urbano-industriais como Rio do Sul, Indaial, Blumenau, Gaspar e Itajaí, que possuem parque industrial diversificado, diversificao, Figura 1 (SANTA CATARINA, 2017). 


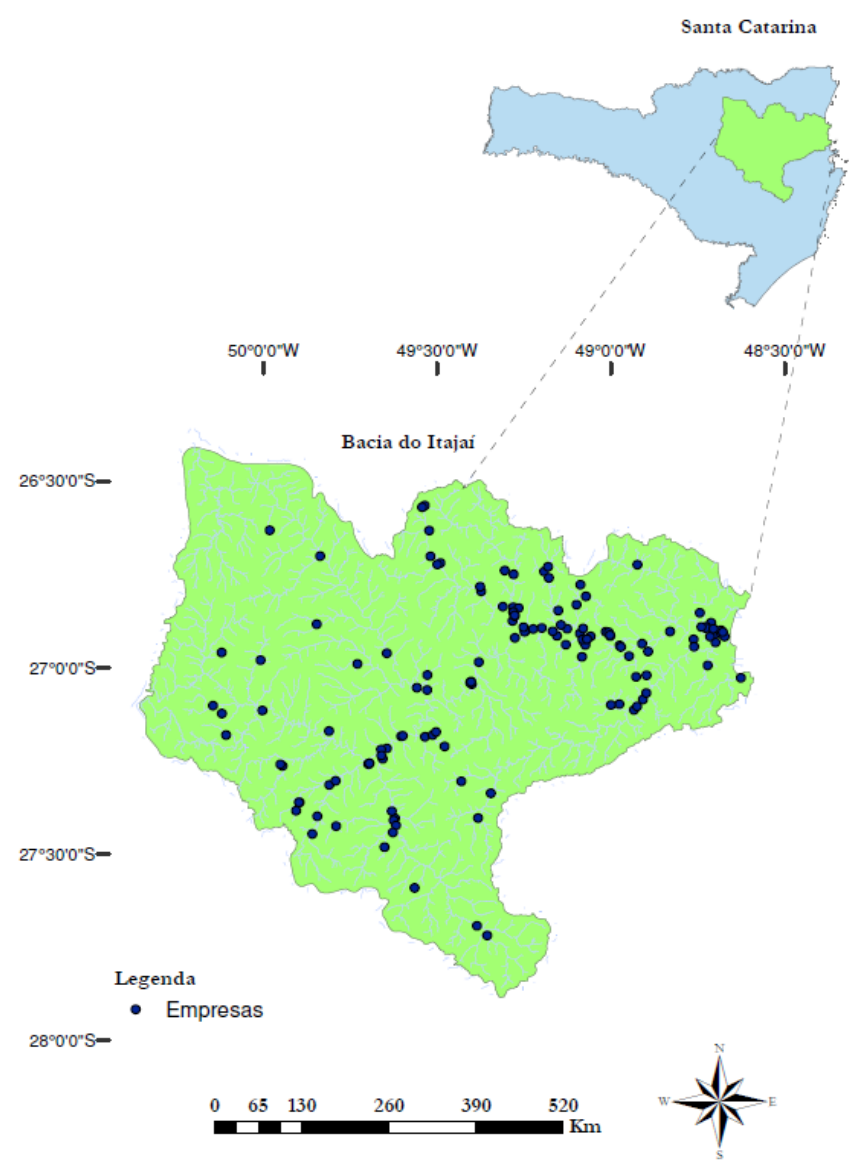

Figura 1 - Pontos de automonitoramento na BHRI

Foram realizadas reuniões com órgãos de fiscalização do Estado de Santa Catarina, que possuem alguma exigência referente ao monitoramento de cursos de água superficial, são eles: IMA, DIRH/SC, Vigilância Sanitária e Polícia Ambiental para esclarecimento de como a informação dos monitoramentos não sistemáticos eram armazenadas. Estes órgãos auxiliaram na disponibilização de informações utilizadas para pesquisa. O IMA forneceu rol de empresas que realizam 0 automonitoramento na BHRI. Posteriormente, foram compilados os laudos de análise de efluentes e água superficial destas empresas, disponíveis no sítio eletrônico do Sistema de Gestão de Protocolo Eletrônico do Governo (SGPE) de Santa Catarina. Estes laudos foram escaneados e disponibilizados em processos por empresas. Posteriormente estes laudos foram transcritos para formato editável para que fosse possível trabalhar com os dados.

A Vigilância Sanitária Estadual cedeu informações da qualidade da água bruta das empresas de abastecimento dos municípios da BHRI. No entanto, há problemas de transferência da informação das vigilâncias municipais para a estadual, sendo necessário, recorrer às próprias empresas de abastecimento para solicitar alguns laudos. Para este trabalho foram utilizados os disponíveis até o momento, totalizando apenas cinco companhias e 38 laudos. A Polícia Ambiental de SC também forneceu acesso ao software GAIA, onde estão disponibilizadas informações de monitoramentos realizados em situações onde há suspeita de infração ambiental. Em quase sua totalidade estas empresas notificadas pela Polícia eram licenciadas pelo IMA.

Foram construídas planilhas para todas as empresas e seus respectivos laudos de análise, encontrados nos diferentes bancos de dados (IMA, Polícia Ambiental, Vigilância Sanitária e empresas de abastecimento em geral). Classificou-se as empresas de acordo com o tipo de monitoramento realizado: somente em seu efluente (ETE), somente em cursos da água (RIO) e ainda aquelas que fazem efluente e curso da água (ETE + RIO). Foi realizada a espacialização dos pontos de captação de manancial superficial utilizado para abastecimento público na BHRI, assim como dos lançamentos de efluentes, figura 1.

Os parâmetros descritos na Resolução CONAMA 357/2005 para águas doces e salobras, Resolução CONAMA 430/2011 e Lei Estadual 14675/2009 além dos demais encontrados nos laudos 
de automonitoramento foram classificados em: físico-químico, nutrientes, biológicos, inorgânicos e orgânicos, conforme tabelas 1-5, respectivamente. Os laudos são do período de 2006 - 2018, no entanto, a maior quantidade destes referem-se ao período a partir de 2012, onde iniciou-se o protocolo eletrônico no IMA. Trabalhou-se com 4947 laudos de 216 empresas. Foram totalizadas a quantidade de análises realizadas por cada parâmetro, assim como, em função dessa quantidade, foi feito um ordenamento por parâmetro, do mais frequente (maior quantidade de análises realizadas) para o menos frequente. A partir da organização desse banco de dados, foi possível verificar os parâmetros mais solicitados e confrontar os mesmos com a legislação vigente.

Para ilustrar a distribuição dos 25 parâmetros com maior número de análises realizadas e a relação com a legislação: Resolução CONAMA 357/2005, CONAMA 430/2011 e Lei Estadual $14675 / 2009$ ou ainda com nenhuma delas, foi realizada uma análise de componente principal pelo método de correlação. 0 eixo das ordenadas está relacionada a quantidade de vezes que o parâmetro foi solicitado, enquanto que o eixo das abcissas as legislações, ou nenhuma delas.

\section{RESULTADOS E DISCUSSÃO}

Foram totalizadas em 216 empresas licenciadas pelo IMA e que realizam o automonitoramento, distribuídas pela região da BHRI. Destas, 134 empresas realizaram automonitoramento apenas dos seus lançamentos, ou seja, de sua estação de tratamento de efluente (ETE). Dezenove empresas fizeram as análises da qualidade da água dos rios e outras 63 empresas fizeram análises tanto da ETE quanto dos pontos à montante e jusante de seu lançamento. A Polícia Ambiental possuía informação da qualidade de água referente à 16 empresas da BHRI.

Foi verificada a frequência média de análises realizadas pelas empresas potencialmente poluidoras e fiscalizadas pelo IMA, Tabela 1. As empresas que possuem maior número de análises são as que monitoram o seu efluente e o corpo receptor do mesmo. Provavelmente isso acontece porque a cada monitoramento são feitas análises do efluente, e de pelo menos um ponto à montante e à jusante do ponto de captação no rio, ou seja, em um mesmo monitoramento são gerados três laudos distintos.

Tabela 1 - Total de análises das empresas potencialmente poluidoras (IMA).

\begin{tabular}{|c|c|c|c|c|}
\hline Análises & $\begin{array}{c}\text { Quantidade } \\
\text { empresas }\end{array}$ & $\begin{array}{l}\text { Total de } \\
\text { Análises }\end{array}$ & Período & $\begin{array}{c}\text { Total de análises por } \\
\text { empresa (média) }\end{array}$ \\
\hline ETE & 134 & 1539 & nov/2006 a jul/2017 & 11,5 \\
\hline ETE + RIO & 63 & 3250 & maio/2008 a jul/2017 & 51,6 \\
\hline RIO & 19 & 158 & jun/2013 a jul/2018 & 8,3 \\
\hline
\end{tabular}

Fonte: Autores (2018).

Das 14 empresas potencialmente poluidoras, que monitoram os cursos da água superficial, RIO, (Tabela 2), observou-se que 4 destas realizaram apenas uma análise, em um único dia. Esse fato pode ser relacionado à obtenção da licença prévia ou de instalação, o que pode acarretar à não entrada em funcionamento da mesma ou a terceirização do tratamento de seus efluentes. Observa-se também, que outras empresas apresentam um largo espaço de tempo entre um monitoramento e outro. Há que salientar também, que o lançamento de efluentes não pode alterar a classe do rio, desta forma, deveria ser efetuada com maior frequência a análise da água do rio após a zona de mistura, com o intuito demonstrar o cumprimento desse quesito (BRASIL, 2011). Outra questão que cabe ser discutida é que a periocidade média em dias é bastante elevada, chegando a ser feita menos de uma ou duas vezes ao ano, o que é insuficiente para uma análise temporal da situação. Demonstra-se assim, que este tipo de monitoramento somente está sendo feito para cumprir a legislação, abdicando do intuito de análise da qualidade da água e do impacto da empresa sobre o recurso hídrico.

Tabela 2 - Automonitoramento realizado por empresas classificadas como RIO

\begin{tabular}{cc|c|c|cc}
\hline \multirow{2}{*}{ Empresa } & $\begin{array}{c}\text { Dias } \\
\text { monitorados }\end{array}$ & Período inicial & Período final & Dias & $\begin{array}{c}\text { Periodicidade } \\
\text { média em dias }\end{array}$ \\
\hline 1 & 3 & out $/ 16$ & $\mathrm{mar} / 17$ & 157 & 79 \\
\hline 2 & 3 & $\mathrm{ago} / 13$ & $\mathrm{dez} / 13$ & 122 & 61 \\
\hline 3 & 1 & $\mathrm{abr} / 14$ & $\mathrm{abr} / 14$ & 0 & 0 \\
\hline 4 & 2 & $\mathrm{nov} / 13$ & $\mathrm{jan} / 14$ & 59 & 59 \\
\hline
\end{tabular}


(Continuação)

\begin{tabular}{|c|c|c|c|c|c|}
\hline Empresa & $\begin{array}{c}\text { Dias } \\
\text { monitorados }\end{array}$ & Período inicial & Período final & Dias & $\begin{array}{l}\text { Periodicidade } \\
\text { média em dias }\end{array}$ \\
\hline 5 & 1 & $\operatorname{mar} / 17$ & mar/17 & 0 & 0 \\
\hline 6 & 2 & set/15 & mar/16 & 182 & 182 \\
\hline 7 & 2 & abr/15 & ago/16 & 488 & 488 \\
\hline 8 & 3 & abr/15 & jul/16 & 457 & 229 \\
\hline 9 & 2 & jan/15 & ago/16 & 578 & 578 \\
\hline 10 & 1 & out/14 & out/14 & 0 & 0 \\
\hline 11 & 2 & nov/16 & $\mathrm{dez} / 16$ & 30 & 30 \\
\hline 12 & 1 & jun/13 & jun/13 & 0 & 0 \\
\hline 13 & 3 & $\mathrm{mar} / 14$ & nov/15 & 610 & 305 \\
\hline 14 & 7 & Jun/15 & Dez/16 & 541 & 91 \\
\hline
\end{tabular}

Fonte: Autores (2018).

Um problema frequente encontrado em diversos laudos foi a falta de informações sobre as condições da amostragem, como horário e temperatura do ar e da água. Assim como, muitas vezes, não estavam presentes a classificação do curso da água em questão, se é doce, salina ou salobra, informação importante para os parâmetros de referência presentes na Resolução CONAMA 357/2005. Além disso, muitos laudos estavam sem informação do ponto amostral georreferenciado. Mesmo utilizando ferramentas geoespaciais, em vários casos não foram encontrados os locais de monitoramento com facilidade, sendo necessária a comunicação direta com as empresas para confirmar o ponto. Esse tipo de informação deveria estar presente em todos os laudos, aumentando a confiabilidade da amostragem.

Alguns parâmetros apresentaram problemas relacionados às unidades, ou seja, as unidades utilizadas pelos laboratórios eram diferentes do que consta na legislação. No caso da salinidade, por exemplo, haviam laudos onde os valores apareciam em percentagem e não em permilagem. Em vários laudos, o mesmo parâmetro apresentava duas unidades diferentes. Alguns apresentavam os resultados com a unidade em micrograma por litro $(\mu / L)$ similares aos valores das legislações, que apresentavam a unidade em miligrama por litro $(\mathrm{mg} / \mathrm{L})$, o que gerou dúvida em relação ao valor apresentado.

Os parâmetros relacionados à presença de bactérias como coliformes termotolerantes, coliformes totais, Escherichia Coli e Salmonella, por exemplo, possuíam as unidades UFC/100mL ou NMP $/ 100 \mathrm{~mL}$. De acordo com Standard Methods for the Examination of Water and Wastewater (2012), NMP refere-se a número mais provável, e estima a densidade de coliformes na amostra. Enquanto que a unidade UFC $/ 100 \mathrm{~mL}$ mede quantas unidades formam colônias de bactérias em cada $100 \mathrm{~mL}$ de água. No entanto, não é possível fazer uma relação de conversão entre essas duas unidades, já que os métodos de obtenção do resultado são muito distintos. Essa situação dificulta a interpretação dos laudos tanto no histórico de um mesmo ponto quanto ao longo dos trechos de um rio.

Em alguns laudos os laboratórios utilizaram as siglas N/A (não aplicado), N/D (não detectado), N/C (não consta) e N/R (não realizado). Percebe-se a falta de padronização de informações dos laudos entre os diversos laboratórios. Assim, neste trabalho considerou-se N/R igual a N/A e N/D igual a N/C. Foi perceptível a necessidade dos laboratórios utilizarem as mesmas metodologias de amostragem e análise. Assim, independente do laboratório que efetua o monitoramento, os resultados obtidos poderão ser comparados com menor incerteza; já que terão sido coletados, armazenados e analisados nas mesmas condições e possuindo as mesmas unidades.

Do total de informação de qualidade de água dos rios da BHRI, obtidos nos bancos de dados consultados chegou-se a um total de 250 parâmetros. Estes foram classificados e totalizados (Tabela 3). Ressalta-se que nem todos os parâmetros encontrados estão presentes nas legislações pertinentes à qualidade e monitoramento dos recursos hídricos superficiais.

Tabela 3 - Classificação dos parâmetros adotados na pesquisa.

\begin{tabular}{c|c|c|c|c}
\hline $\begin{array}{c}\text { Classificação } \\
\text { parâmetro }\end{array}$ & Laudos & $\begin{array}{c}\text { CONAMA no } \\
\mathbf{3 5 7 / 2 0 0 5}\end{array}$ & $\begin{array}{c}\text { CONAMA no } \\
\mathbf{4 3 0 / 2 0 1 1}\end{array}$ & $\begin{array}{c}\text { Lei Estadual } \\
\mathbf{1 4 6 7 5 / 2 0 0 9}\end{array}$ \\
\hline Físico-químico & 37 & 15 & 10 & 4 \\
\hline Biológico & 14 & 2 & 1 & - \\
\hline
\end{tabular}


(Continuação)

\begin{tabular}{c|c|c|c|c}
\hline $\begin{array}{c}\text { Classificação } \\
\text { parâmetro }\end{array}$ & Laudos & \multicolumn{1}{c}{$\begin{array}{c}\text { CONAMA no } \\
\mathbf{3 5 7 / 2 0 0 5}\end{array}$} & $\begin{array}{c}\text { CONAMA no } \\
\mathbf{4 3 0 / 2 0 1 1}\end{array}$ & $\begin{array}{c}\text { Lei Estadual } \\
\mathbf{1 4 6 7 5 / 2 0 0 9}\end{array}$ \\
\hline Nutrientes & 12 & 6 & 1 & - \\
\hline Inorgânicos & 48 & 27 & 20 & 11 \\
\hline Orgânicos & 139 & 56 & 10 & 4 \\
\hline
\end{tabular}

Fonte: Autores (2018)

Avaliando-se os laudos, percebeu-se que empresas do mesmo ramo de atividade possuíam exigências distintas em relação ao seu automonitoramento, seja parâmetros ou periodicidade das análises. Isso pode ocorrer em função de três fatores: processo produtivo específico da empresa em questão; porte da empresa ou ainda em função do responsável técnico no órgão ambiental. Isto porque, fica a critério do responsável técnico a eleição dos parâmetros e da periodicidade dos mesmos. Neste contexto, nota-se a necessidade de haver normativa para orientar os diversos técnicos do órgão ambiental na eleição de parâmetros para análise de efluentes e rios por ramo de atividade e porte da empresa.

Os parâmetros presentes para água doce e salobra na Resolução CONAMA 357/2005, Resolução CONAMA 430/2011 e Lei Estadual 145675/2009, assim como aqueles presentes nos laudos foram classificados em físico-químicos, nutrientes, biológicos, inorgânicos e orgânicos. Estes foram organizados pela presença nas distintas legislações citadas. Além disso, os parâmetros estão ordenados pela sua posição frente aos 250 parâmetros encontrados, primeiro número que aparece ao lado de cada parâmetro, e totalizados pela quantidade de análise, segundo número ao lado de cada parâmetro, tabela 4-10.

Tabela 4 - Parâmetros de qualidade de água, sua respectiva ordenação e frequência, encontrados nas Resoluções CONAMA 357/2005, CONAMA 430/2011 e Lei Estadual 14675/2009

\begin{tabular}{|c|c|c|c|c|}
\hline Físico-químicos & Nutrientes & Biológicos & Inorgânicos & Orgânicos \\
\hline $\begin{array}{l}\mathrm{pH}(2 ; 4088) \text {; Materiais } \\
\text { flutuantes }(35 ; 583) ; \\
\text { Materiais sedimentáveis } \\
(225 ; 3) .\end{array}$ & Não consta & $\begin{array}{c}\text { Coliformes } \\
\text { termotolerantes }(13 ; \\
\text { 1597); Densidade de } \\
\text { cianobactérias }(90 ; 66) .\end{array}$ & $\begin{array}{c}\text { Zinco total }(19 ; 1137) ; \\
\text { cádmio total }(40 ; 532) ; \\
\text { níquel total }(43 ; 481) ; \\
\text { Mercúrio total }(49 ; 399) ; \\
\text { Arsênio total }(56 ; 219) ; \\
\text { Selênio total }(58 ; 207) ; \text { Prata } \\
\text { total }(63 ; 159)\end{array}$ & Não consta \\
\hline
\end{tabular}

Fonte: Autores (2018)

Tabela 5 - Parâmetros de qualidade de água, sua respectiva ordenação e frequência, encontrados nas Resoluções CONAMA 357/2005 e CONAMA 430/2011

\begin{tabular}{|c|c|c|c|c|}
\hline Físico-c & Nutı & iológicos & Inorgânicos & Orgânicos \\
\hline $\begin{array}{l}\text { DBO }(1 ; 4264) ; \text { Óleos } \\
\text { Minerais }(16 ; 1243) ; \\
\text { Sólidos grosseiros e } \\
\text { materiais flutuantes } \\
\qquad(244 ; 0)\end{array}$ & $\begin{array}{c}\text { Nitrogênio } \\
\text { amoniacal total } \\
(9 ; 1927)\end{array}$ & Não & $\begin{array}{c}\text { Cobre dissolvido }(31 ; 651) ; \\
\text { Ferro dissolvido }(34 ; 588) ; \\
\text { Chumbo total }(41 ; 523) ; \\
\text { Bário total }(59 ; 192) ; \\
\text { Fluoreto total }(60 ; 190) ; \\
\text { Cianeto livre }(67 ; 137) ; \\
\text { Boro total }(72 ; 127)\end{array}$ & $\begin{array}{c}\text { Fenóis totais }(14 ; 1527) ; \\
\text { Benzeno }(71 ; 132) ; \text { Tolueno } \\
(74 ; 126) ; \text { Xileno }(77 ; 113) ; \\
\text { Etilbenzeno }(78 ; 105) ; \\
\text { Tetracloreto de carbono } \\
(81 ; 95) ; \text { Tricloroeteno } \\
(82 ; 95) ; \text { Estireno }(91 ; 66)\end{array}$ \\
\hline
\end{tabular}

Fonte: Autores (2018).

Tabela 6 - Parâmetros de qualidade de água, sua respectiva ordenação e frequência, encontrados na Resolução CONAMA 357/2005 e Lei Estadual 14675/2009

\begin{tabular}{c|c|c|c|c}
\hline Físico-químicos & Nutrientes & Biológicos & \multicolumn{1}{c}{ Inorgânicos } & Orgânicos \\
\hline Não consta & Não consta & Não consta & Não consta & $\begin{array}{c}\text { Surfactantes aniônicos } \\
(8 ; 2044)\end{array}$ \\
\hline Fonte: Autores (2018).
\end{tabular}


Tabela 7 - Parâmetros de qualidade de água, sua respectiva ordenação e frequência, encontrados na Resolução CONAMA 430/2011 e Lei Estadual 14675/2009

\begin{tabular}{c|c|c|c|c}
\hline Físico-químicos & Nutrientes & Biológicos & \multicolumn{1}{c}{ Inorgânicos } & Orgânicos \\
\hline $\begin{array}{c}\text { Óleos Vegetais e } \\
\text { Gorduras Animais } \\
(33 ; 604)\end{array}$ & Não consta & Não consta & $\begin{array}{c}\text { Cromo hexavalente } \\
(27 ; 733)\end{array}$ & Não consta \\
\hline
\end{tabular}

Fonte: Autores (2018).

Tabela 8 - Parâmetros de qualidade de água, sua respectiva ordenação e frequência, encontrados na Resolução CONAMA 357/2005

\section{Parâmetros físico-químicos}

Óleos e Graxas (7;2431); Turbidez (11;1666); OD (15;1349); Cor verdadeira (20;1117);

Sólidos dissolvidos totais (44;463); Corantes provenientes de fontes antrópicas(244;0); Odor e aspecto(244;0); Substâncias que comuniquem gosto ou odor(244;0); Substâncias que produzem cor, odor e turbidez(244;0).

Nutrientes

Fósforo total(4;2994); Nitrato (18;1146); Nitrito (23;972); Carbono orgânico total (219;4); Polifosfatos (244;0) Parâmetros biológicos

Coliformes termotolerantes (13; 1597); Densidade de cianobactérias $(90 ; 66)$

\section{Parâmetros Inorgânicos}

Cromo total (24;963); Alumínio dissolvido (26;868); Manganês total (47;422); Cloreto total (53;330); Sulfato total (57;218); Cobalto total (73;126); Sulfetos (como H2S não dissociado); (87;77); Antimônio (89;71); Cloro residual total (combinado + livre); $(95 ; 59)$; Berílio total $(98 ; 54)$; Lítio total $(105 ; 47)$; Vanádio total $(111 ; 45)$; Urânio total (119;40);

\section{Parâmetros Orgânicos}

Clorofila-a(28;722); Pentaclorofenol(65;139); 2,4,6-Triclorofenol(66;137); 2-Clorofenol(68;134); 2,4-Diclorofenol(69;133); 1,1-Dicloroeteno(93;62); Diclorometano(96;57); Benzo(a)pireno(97;56); Benzo(a)antraceno(99;51);

Dibenzo(a,h)antraceno(101;51); Indeno(1,2,3-cd); pireno(102;51); 1,2-Dicloroetano(103;50);

Tetracloroeteno(104;49); PCBs-Bifenilas Policloradas(106;47); Benzo(b)fluoranteno(108;45);

Benzo(k)fluoranteno(109;45); Aldrin+Dieldrin(112;44); DDT(p,p'-DDT+p,p'-DDE+p,p'-DDD) (114;44);

Endrin(115;44); Lindano (gama-HCH);(116;43); Criseno(118;40); Hexaclorobenzeno(120;39); Acrilamida(121;38);

Alacloro(122;38); Atrazina(123;38); Endossulfan(alfa+beta+sulfato);(124;38); Glifosato(126;37);

Metolacloro(128;37); 2,4,5-T(129;36); 2,4-D(130;36); Trifluralina(132;36); Simazina(134;35);

Clordano(cis+trans)(135;34); Benzidina(136;33); Carbaril(137;33); Gution(138;33);

Heptacloroepóxido+Heptacloro(139;33); Malation(140;33); Metoxicloro(141;33);

Paration(142;33); Toxafeno(143;33); 2,4,5-TP(144;32); Demeton(Demeton-0+Demeton-S) (146;32); Dodecacloro

Pentaciclodecano(147;32); Tributilestanho(148;32); 3,3-Diclorobenzidina(150;29); Triclorobenzeno(1,2,3-

TCB+1,2,4-TCB);(152;28)

Fonte: Autores (2018).

Tabela 9 - Parâmetros de qualidade de água, sua respectiva ordenação e frequência, encontrado na Resolução CONAMA 430/2011

\begin{tabular}{|c|c|c|c|c|}
\hline Físico-químicos & Nutrientes & Biológicos & Inorgânicos & Orgânicos \\
\hline $\begin{array}{l}\text { Temperatura }(6 ; 2486) ; \\
\text { Sólidos em suspensão } \\
\text { totais }(30 ; 658) ; \\
\text { Vazão }(76 ; 118)\end{array}$ & Não consta & $\begin{array}{c}\text { Ecotoxicidade } \\
(21 ; 1103)\end{array}$ & $\begin{array}{c}\text { Sulfeto(61;171); Cromo } \\
\text { trivalente(62;169); } \\
\text { Cianeto total( }(64 ; 139) ; \\
\text { Estanho total(75;123); } \\
\text { Manganês } \\
\text { dissolvido }(94 ; 60)\end{array}$ & $\begin{array}{l}\text { Clorofórmio }(100 ; 51) \\
\text { Dicloroeteno }(153 ; 25)\end{array}$ \\
\hline
\end{tabular}

Fonte: Autores (2018).

Tabela 10 - Parâmetros de qualidade de água, sua respectiva ordenação e frequência, encontrado na Lei Estadual 14675/2009

\begin{tabular}{|c|c|c|c|c|}
\hline Físico-químicos & Nutrientes & Biológicos & Inorgânicos & Orgânicos \\
\hline Não consta & Não consta & Não consta & $\begin{array}{c}\text { Cobre total }(48 ; 411) ; \\
\text { Sulfeto de carbono } \\
(154 ; 22) ; \text { Manganês } \\
+2 \text { solúvel }(244 ; 0) .\end{array}$ & $\begin{array}{c}\text { Organoclorados } \\
(155 ; 20) ; \text { Compostos } \\
\text { organofosforados e } \\
\text { Carbamatos }(158 ; 20) \\
\text { Etileno }(165 ; 15)\end{array}$ \\
\hline
\end{tabular}

Fonte: Autores (2018). 
Outro aspecto que apareceu nesse levantamento é a quantidade de parâmetros monitorados pelas empresas, exigidos especialmente pelo órgão ambiental, e que não constam em nenhuma das legislações previamente citadas, tabela 11. 0 terceiro, quinto e o décimo parâmetro mais frequentes, DQO, sólidos sedimentáveis e cor aparente, respectivamente, não constam em nenhuma das três legislações avaliadas, mas destacam-se pela quantidade de análises realizadas, figura 2 .

Tabela 11 - Parâmetros de qualidade de água, sua respectiva ordenação e frequência, que não constam na legislação

Parâmetros físico-químicos

DQ0 (3; 3495); Sólidos Sedimentáveis (5; 2793); Cor aparente $(10 ; 1916)$; Salinidade $(36 ; 583) ;$ COP (39; 543); Condutividade Elétrica $(45 ; 445)$; Sólidos Totais $(46 ; 437)$;

Sólidos Suspensos Voláteis $(51$; 352); Sólidos Suspensos Fixos (52 ; 344); Óleos e graxas vegetais (54; 267); Alcalinidade total $(70 ; 133)$; Temperatura da Água (83 ; 93); Dureza Total $(117 ; 41)$; Acidez total $(133 ; 35)$; Sólidos Fixos Totais (157 ; 20); Sólidos Voláteis Totais (159; 19); Sólidos Dissolvidos Fixos (184 ; 8); Sólidos Dissolvidos Voláteis $(185 ; 8)$

\section{Nutrientes}

Nitrogênio Kjeldahl total(17;1215); Nitrogênio total(25;946); Fosfato(29;691); Amônia(32;615); Nitrogênio Orgânico(149;30); Nitrogênio Inorgânico(177;11)

$$
\text { Parâmetros biológicos }
$$

Coliformes Totais(12;1602); Ecotoxicidade aguda em Vibrio fischeri(38;563); Ecotoxicidade aguda em Daphnia Magna(42;511); Escherichia Coli(55;239); Fitoplâncton(107;46); Salmonella(110;45); Ecotoxicidade crônica com Desmodesmus subspucatus(151;29); Zooplâncton(162;18); Bactérias heterotróficas(163;15);

Zoobentos(175;12); Zooplancton com rede(187;8)

Parâmetros Inorgânicos

Ferro total (22;999); Silício(50;394); Sódio(88;75); Ítrio(92;63); Cálcio(113;44); Potássio(125;38); Magnésio(127;37); Cloro Residual Livre(131;36); Cloro total(164;15); Sulfitos(174;12); Molibdênio(183;8); Tálio total(186;8)

$$
\text { Parâmetros Orgânicos }
$$

Surfactantes(37;570); 2,4 - Dimetilfenol(79;95); 2,6 - Diclorofenol(80;95);2,3,4,5 - Tetraclorofenol(84;91); 2,3,4,6 - Tetraclorofenol(85;91);2,4,5 - Triclorofenol(86;91); Carbamatos(145;32);Organofosforados(156;20); Fenantreno(160;18); Naftaleno(161;18); Acenafteno(166;12); Acenaftileno(167;12); Antraceno(168;12); Benzo(g,h,i)pireno(169;12); Enterococcus spp.(170;12); Fluoranteno(171;12); Fluoreno(172;12); Pireno(173;12);

cis 1,2-Dicloroeteno(176;11); 1,1,1-Tricloroetano(178;10); 1,2-Diclorobenzeno(179;10); 1,4-Diclorobenzeno(180;10); Cloreto de Vinila(181;10); 1,2 - Dicloroeteno (cis + trans);(182;8); 1,1-Dicloroetano(188;7); 1,2,3 - Triclorobenzeno(189;6); 1,2,4 - Triclorobenzeno(190;6); 1,3,5 - Triclorobenzeno(191;6); 3,4 - Diclorofenol(192;6); Cloreto de Metileno(193;6); Cresóis(194;6); Dietilexil Ftalato(195;6); Dimetil Ftalato(196;6); Monoclorobenzeno(197;6); Tricloroetileno(198;6); 1,1,1,2-Tetracloroetano(199;5); Bromodiclorometano(200;5); cis 1,3Dicloropropeno(201;5); trans 1.2-Dicloroeteno(202;5); Trans 1.3-Dicloropropeno(203;5); Trihalometanos Totais(204;5); 1,3-Diclorobenzeno(205;4);2,2,3,3,4,4,5,5 - Octaclorobifenil(206;4); 2,2,3,4,4,5Hexaclorobifenil(207;4); 2,2,3,4,5,6-Hexaclorobifenil(208;4); 2,2,3,5 -Tetraclobifenil(209;4); 2,2,4,4,5,5Hexaclorobifenil(210;4); 2,2,4,5,5-Pentaclorobifenil(211;4); 2,2,5 - Triclorobifenil(212;4); 2,2,5,5Tetraclorobifenil(213;4); 2,3,4,4,5-Pentaclorobifenil(214;4); 2,4,4 -Triclorobifenil(215;4);2,4,5 Triclorobifenil(216;4); Bromobenzeno(217;4); Bromofórmio(218;4); Clorobenzeno(220;4); Dibromoclorometano(221;4); Diclorodifluorometano(222;4); Triclorobenzenos (1.2.4 TCB + 1.3.5 TCB + 1.2.3 TCB) $(223 ; 4)$; Ácidos haloacéticos total(224;3); Triclorofluorometano(226;3); 1,1,1- Tricloroetano(227;2); 1,1,2 - Tricloroetano(228;2); 1,1,2-Tricloroetano(229;2); 2,4 D + 2,4,5 T(230;2); Hidrocarbonetos Totais (231;2); 1,1,2,2-Tetracloroetano(232;1); 1,2,3-Tricloropropano (233;1); 1,2-Dicloropropano (234;1); 2,4Dinitrotolueno (235;1); Compostos Organo halogenados Adsorvíveis (236;1); Dibromometano(237;1); Epicloridrina(238;1); Hexaclorobutadieno(239;1); Hexacloroetano(240;1); Nitrobenzeno(241;1); Piridina(242;1); Tricloroetano(243;1) 


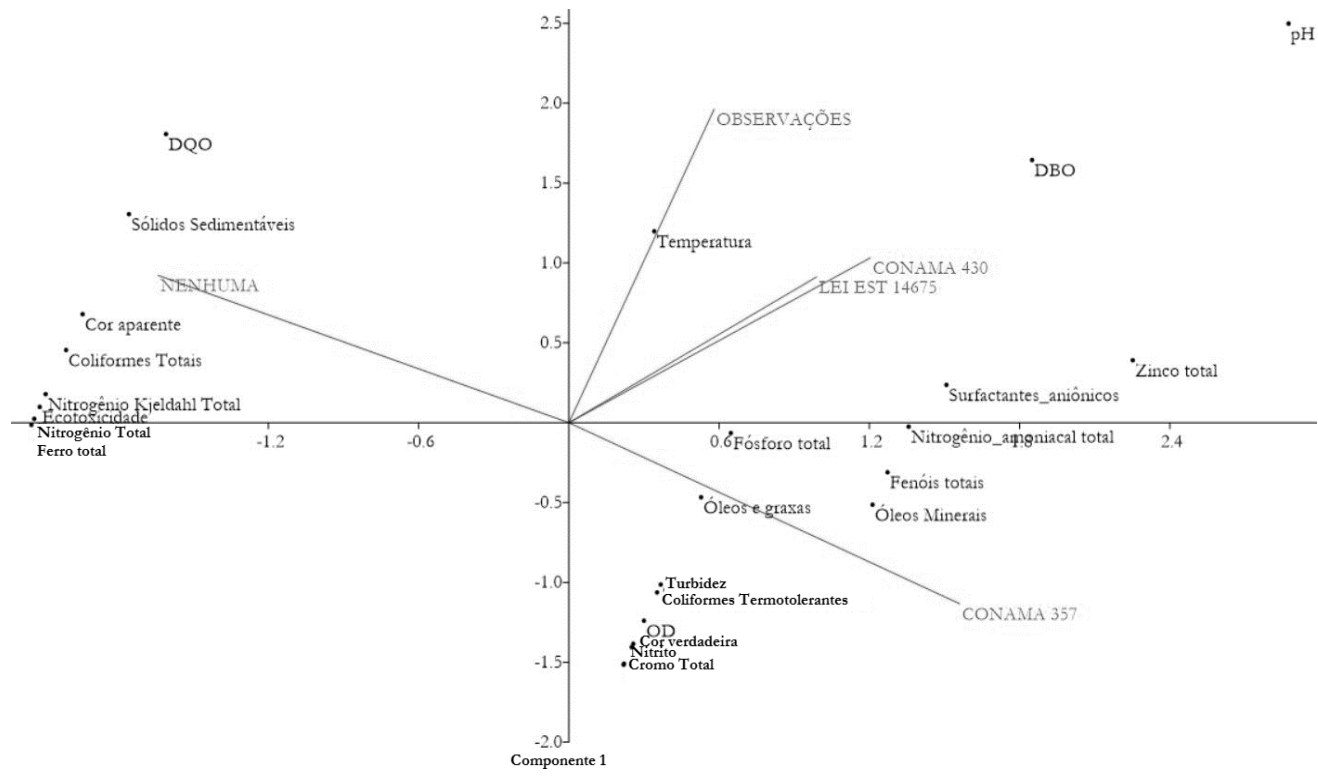

Figura 2 - Quantidade de análises realizadas dentre os 25 parâmetros mais frequentes frente às legislações.

O nitrogênio Kjedahl total, que é a soma do nitrogênio amoniacal com o orgânico (UNITED STATES ENVIRONMENTAL PROTECTION AGENCY, 1993), é o 17ํㅡ parâmetro mais frequente, apesar da legislação constar apenas o nitrogênio amoniacal total. 0 mesmo ocorre com nitrogênio total, fosfato, amônia, nitrogênio orgânico e inorgânico. Ou seja, 58\% dos parâmetros classificados como nutrientes não constam nas legislações, mas são realizadas análises. Cabe destacar que estes parâmetros são bastante relevantes por estarem relacionados à presença de lançamento de esgotos sanitários (LAMEGO NETO; COSTA, 2011; SAMPAIO et al., 2017).

Ao total, dos 38 parâmetros físico-químicos, 18 não estão presentes nas legislações, o que demonstra um desalinhamento entre esta e as exigências do órgão ambiental. Algumas análises organolépticas, apesar de estarem descritas na legislação e serem de fácil execução, não estão sendo executadas. A vazão que é uma variável extremamente relevante para o cálculo das cargas lançadas em um rio, principalmente porque a maioria dos laudos são de efluentes, aparece apenas na $76^{\text {a }}$ posição, estando presente em apenas 118 das 4947 análises.

Dentre os 14 parâmetros classificados como biológicos apenas três estão presentes na legislação. No entanto, todos são solicitados pelos órgãos ambientais. Destaca-se o coliforme total, apresentandose como o $12^{\circ}$ parâmetro mais recorrente. Cabe destacar que a ecotoxicidade é solicitada na legislação, mas esta não especifica como a mesma deve ser realizada, aparecendo de forma específica nos laudos. Por este motivo que, considerando-se as três análises distintas de ecotoxicidade que foram encontradas, chegou-se ao valor total de 1103. É interessante que o órgão ambiental esteja solicitando o monitoramento de parâmetros biológicos. Isso porque a Diretiva 60 (EUROPEAN COMMISSION, 2000) instrumento político referente à qualidade da água na União Europeia, trabalha com a classificação dos corpos da água superficial por elementos biológicos, além dos hidromorfológicos, químicos e físico-químicos (CARRÉ et al., 2017).

Nos laudos dos parâmetros inorgânicos, o ferro total destaca-se como o segundo mais frequente dessa categoria, apesar de não estar especificado nas legislações estudadas. Assim como o ferro, mas com menor destaque, aparecem os parâmetros: ítrio, potássio, magnésio, cloro residual livre, cloro total, sulfitos, molibdênio e tálio total. Nos laudos não apareceu análise específica do cátion $\mathrm{Mn}^{+2}$, conforme Lei Estadual 14675/2009, apenas manganês total e dissolvido, apesar de esta ser a forma mais abundante nessa fração.

Nos laudos dos laboratórios pesquisados, a nomenclatura utilizada para a determinação de resíduo sedimentável é sólido sedimentável, conforme NBR 10561 (ASSOCIAÇÃO BRASILEIRA DE NORMAS TÉCNICAS, 1988), enquanto que na Lei estadual 146575/2009 e Resolução CONAMA 430/2011 este parâmetro está descrito como materiais sedimentáveis, o qual foi adotada para este trabalho. Em contrapartida, na Resolução CONAMA 357/2005 a nomenclatura é substâncias facilmente sedimentáveis, demonstrando assim ausência de alinhamento de nomenclatura entre as legislações, assim como entre os laboratórios. 
Na Resolução CONAMA 430/2011 está prevista a observação de sólidos grosseiros e materiais flutuantes, enquanto que na Resolução CONAMA 357/2005, consta como resíduos sólidos objetáveis. No entanto, não foi constatada essa análise nos laudos de automonitoramento. Nos laudos aparecem as nomenclaturas sólidos em suspensão, sólidos em suspensão totais e material particulado em suspensão (MPS). Para fins desta análise todos foram contabilizados como sólidos em suspensão total. Este caso demonstra a diversidade de nomenclatura adotada pelos laboratórios que realizam análise de água em Santa Catarina.

Dos dez parâmetros que aparecem com mais frequência, sete são físico-químicos, com destaque para DBO e pH. A DBO é um parâmetro que determina o oxigênio requerido para oxidar a matéria orgânica presente na água (STANDARD METHODS FOR THE EXAMINATION OF WATER AND WASTEWATER, 2012), sendo um indicativo do lançamento de esgotamento sanitário nos corpos hídricos (BUZELLI; CUNHA-SANTINO, 2013). 0 pH é considerado um parâmetro importante para determinar a aptidão da água para vários propósitos, para a vida aquática é considerado ótimo entre 6,5 - 8,2 (MATTA et al., 2017). 0 pH como relaciona a condição de neutralidade, acidez e alcalinidade dos corpos da água, pode influenciar, além dos processos biológicos, os químicos (SOUZA et al., 2013).

A Resolução CONAMA 357/2005 e a Lei Estadual 14675/2009 possuem o parâmetro substâncias tensoativas que reagem com azul de metileno. No entanto, na maioria dos laudos esta análise aparece como surfactantes aniônicos, sendo este o $8^{\circ}$ parâmetro mais frequente no geral. Dentre os 50 parâmetros mais presentes, apenas 4 foram classificados como orgânicos: surfactantes aniônicos, fenóis totais, clorofila a e surfactantes.

Na Lei Estadual 14675/2009 é contabilizado conjuntamente os compostos organofosforados e carbamatos, no entanto os laudos apresentam essas análises separadamente, provavelmente por tratar-se de análises distintas. 0 mesmo ocorre com o parâmetro descrito como "outros compostos organoclorados", que nos laudos são descritos como organoclorados, nomenclatura esta adotada na tabela 10. Nos parâmetros orgânicos também se destacam os que são solicitados pelo órgão ambiental e que não constam nas legislações estudadas, totalizando 78 de 139, ou seja, 56\%. Dos parâmetros presentes na legislação, o que houve menor frequência de análise é o etileno, mas que ainda aparece em 15 laudos. Evidencia-se também que 55 parâmetros orgânicos foram requisitados em menos de 10 análises.

Essas situações relatadas demonstram a falta de alinhamento entre as legislações, assim como entre essas e as exigências dos órgãos ambientais. Ressaltando-se a importância de uma discussão sobre uma possível revisão das legislações pertinentes e de normativas de trabalho para os órgãos de fiscalização e controle.

\section{CONCLUSÕES}

Nos laudos das empresas avaliadas, a periodicidade entre uma análise e outra é bastante variável, assim como em alguns casos foi realizada apenas uma análise por empresa. Outro aspecto relevante é a ausência de informação sobre a vazão de lançamento dos efluentes, assim como, a qualidade da água dos corpos receptores após a zona de mistura.

É importante notar como há parâmetros solicitados pelos órgãos de fiscalização e controle e que não constam nas legislações voltadas à qualidade de água dos rios. Dentre esses parâmetros, destacaram-se DQO, sólidos sedimentáveis, cor aparente, nitrogênio Kjedahl, coliformes totais e ferro total. Mais de 50\% dos parâmetros orgânicos e biológicos que constam nos laudos avaliados não constam nas legislações estudadas. Evidencia-se a necessidade de realinhamento dos procedimentos operacionais dentro dos próprios órgãos, alinhando a cobrança dos parâmetros com a legislação vigente. Além de melhorar a uniformidade entre os parâmetros e periodicidade requerida das empresas. Também se observa a possibilidade de revisão da legislação e inserção e exclusão de parâmetros.

Trabalhando-se com laudos de diversos laboratórios, percebe-se a dificuldade de uniformidade, inclusive de nomenclatura, dos documentos entre si e entre a própria legislação vigente. As variações ocorrem também em relação às unidades adotadas. Constatou-se assim, a importância de normatização entre os laboratórios, assim como de metodologias para padronização de monitoramento e métodos de análise. 


\section{AGRADECIMENTOS}

Os autores agradecem a FAPESC (termo de outorga $\mathrm{n}^{\circ}$, 2016TR2525) pelo auxílio financeiro ao projeto intitulado "Programa de Efetivação do Enquadramento da Bacia Hidrográfica do Itajaí" e a Diretoria de Recursos Hídricos da Secretaria de Desenvolvimento Sustentável do Estado de Santa Catarina pelo apoio operacional.

\section{REFERÊNCIAS}

AGÊNCIA NACIONAL DE ÁGUAS - ANA. Conjuntura dos recursos hídricos no Brasil 2017: relatório pleno. Brasília: ANA, 2017. p. 169.

AGÊNCIA NACIONAL DE ÁGUAS - ANA. Cadernos de capacitação em recursos hídricos - v. 5: planos de recursos hídricos e enquadramento dos corpos de água. ANA: Brasília, 2013. Disponível em: <https://capacitacao.ead.unesp.br/dspace/handle/ana/8>. Acesso em: 22 jun. 2018.

ASSOCIAÇÃO BRASILEIRA DE NORMAS TÉCNICAS. NBR 10561. Águas - Determinação de resíduo sedimentável (sólidos sedimentáveis) - Método do cone de Imhoff. Rio de Janeiro, 1988.

BUZELLI, G. M.; CUNHA-SANTINO, M. B. C. Análise e diagnóstico da qualidade da água e estado trófico do reservatório de Barra Bonita, SP. Revista Ambiente \& Água - An Interdisciplinary Journal of Applied Science, v. 8, n. 1, 2013. Disponível em: <http://www.scielo.br/pdf/ambiagua/v8n1/14.pdf>. Acesso em: 27 jul. 2018.

CARRÉ, C.; MEYBECK, M.; ESCULIER, F. The Water Framework Directive's "percentage of surface water bodies at good status": unveiling the hidden side of a "hyperindicator". Ecological Indicators, v. 78, p. 371-380, 2017. Disponível em: <https://bit.ly/2o2dMVq>. Acesso em: 1 ago. 2018.

COELHO, M. et al. Statistical validity of water quality time series in urban watersheds. Revista Brasileira de Recursos Hídricos, Porto Alegre, v. 22, s.n., p. 1-13, 2017. Disponível em: <http://www.scielo.br/pdf/rbrh/v22/2318-0331-rbrh-22-e51.pdf>. Acesso em: 26 jul. 2018.

COMITÊ DO ITAJAÍ. FUNDAÇÃo AGÊNCIA DE ÁGUA DO VALE DO ITAJAÍ. Plano de Recursos Hídricos da Bacia do Itajaí: Documento Síntese, 2010.

CONSELHO ESTADUAL DO MEIO AMBIENTE - CONSEMA. Lei no 14.675, Código Estadual do Meio Ambiente, de 13 de abril de 2009. Disponível em: <http://www.pmf.sc.gov.br/arquivos/arquivos/pdf/20_12_2013_14.30.40.b479cb7a256a963c9e0bbf87bd 860d38.pdf>. Acesso em: 06 mar 2018.

CONSELHO ESTADUAL DE RECURSOS HÍDRICOS - CERH. Resolução no 001, Dispõe sobre a classificação dos corpos de água de Santa Catarina e dá outras providências, 30 de junho de 2008. Disponível em: <http://www.cadastro.aguas.sc.gov.br/sirhsc/conteudo_visualizar_dinamico.jsp?idEmpresa=6\&idMenu=71 4\&idMenuPai=38>. Acesso em: 23 ago. 2018.

BRASIL. CONSELHO NACIONAL DO MEIO AMBIENTE - CONAMA. Resolução no 357, Dispõe sobre a classificação dos corpos de água e diretrizes ambientais para o seu enquadramento, bem como estabelece as condições e padrões de lançamento de efluentes, e dá outras providências de 17 de março de 2005. Brasília, 2005. Disponível em: < http://www.mma.gov.br/port/conama/res/res05/res35705.pdf>. Acesso em: 5 mar. 2018.

BRASIL. CONSELHO NACIONAL DO MEIO AMBIENTE - CONAMA. Resolução no 430, Dispõe sobre as condições e padrões de lançamento de efluentes, complementa e altera a Resolução no 35, de 17 de março de 2005, de 13 de maio de 2011. Brasília, 2011a. Disponível em:

<http://www.mma.gov.br/port/conama/legiabre.cfm?codlegi=646>. Acesso em: 5 mar. 2018.

EUROPEAN COMMISSION - EC. Directive 2000/60/EC of the European Parliament and of the Council of 23 October 2000 establishing a framework for community action in the field of water policy. Official Journal of the European Communities, 2000. Disponível em: <https://publications.europa.eu/en/publication-detail//publication/70e52c10-85a1-4e97-8218-ed56d597ed05/language-en>. Acesso em: 1 ago. 2018.

LAMEGO NETO, L.; COSTA, R. H. R. Tratamento de esgoto sanitário em reator híbrido em bateladas sequenciais: eficiência e estabilidade na remoção de matéria orgânica e nutrientes (N, P). Engenharia Sanitaria e Ambiental, v. 16, n. 4, p. 411-420, 2011. Disponível em: <http://www.scielo.br/scielo.php?script=sci_arttext\&pid=S141341522011000400013\&lng=en\&nrm=iso\&tlng=pt>. Acesso em: 2 ago. 2018.

MATTA, G. et al. Assessment of physicochemical characteristics of Ganga Canal water quality in Uttarakhand. Environment, Development and Sustainability, v. 19, n. 2, p. 419-431, 2017. Disponível em: <https://link.springer.com/article/10.1007/s10668-015-9735-x>. Acesso em 18 jul. 2018. 
BRASIL. MINISTÉRIO DA SAÚDE - MS. Portaria de Consolidação no 5, de 28 de setembro de 2017. Consolidação das normas sobre as ações e os serviços de saúde do Sistema Único de Saúde. Disponível em: <http://portalarquivos2.saude.gov.br/images/pdf/2018/marco/29/PRC-5-Portaria-de-Consolida----o-n--5--de-28-de-setembro-de-2017.pdf>. Acesso em: 30 abr. 2019.

BRASIL. MINISTÉRIO DA SAÚDE - MS. Portaria no 2914, de 12 de dezembro de 2011b. Dispõe sobre os procedimentos de controle e de vigilância da qualidade da água para consumo humano e seu padrão de potabilidade. Disponível em: <http://bvsms.saude.gov.br/bvs/saudelegis/gm/2011/prt2914_12_12_2011.htmll>. Acesso em: 06 mar. 2018.

PESSÔA, Z. B. Efetivação do enquadramento de corpos d'água para fins de consumo humano em regiões semiáridas: avaliação conforme Resolução CONAMA 357/2005 e Portaria MS 2914/2011. 2013. 123 f. Dissertação (Mestrado) - Universidade Federal da Bahia, Salvador, 2013. Disponível em: $<$ https://bit.ly/2Mq5aX2>. Acesso em: 27 jun. 2018.

PIAZZA, G. A. et al. Influence of hydroclimatic variations on solute concentration dynamics in nested subtropical catchments with heterogeneous landscapes. Science of the total environment, v. 635, p. 1091-1101, 2018. Disponível em: < https://www.sciencedirect.com/science/article/pii/S0048969718311549>. Acesso em: 2 ago. 2018.

PROGRAMA MUNDIAL DE LAS NACIONES UNIDAS DE EVALUACIÓN DE LOS RECURSOS HÍDRICOS WWAP/ONU-Agua. Informe Mundial de las Naciones Unidas sobre el Desarrollo de los Recursos Hídricos 2018: Soluciones basadas en la naturaleza para la gestión del agua. París: UNESCO, 2018. Disponível em: <http://unesdoc.unesco.org/images/0026/002614/261494s.pdf>. Acesso em: 16 jul 2018.

QUALIAGUA. Portal da qualidade da água. Disponível em: <http://portalpnqa.ana.gov.br/Qualiagua.aspx>. Acesso em: 17 jul. 2018.

SAMPAIO, C. R. et al. Avaliação da qualidade ambiental do Rio dos Bugres, complexo estuarino de Santos e São Vicente (São Paulo, Brasil). UNISANTA Bioscience, v. 6, n. 4, p. 248-257, 2017.

SANTA CATARINA. SECRETARIA DE ESTADO DO DESENVOLVIMENTO ECONÔMICO E SUSTENTÁVEL. Recursos hídricos de Santa Catarina. Florianópolis: Sistema de Informações de Recursos Hídricos do Estado de Santa Catarina, 2017. Disponível em: <http://www.aguas.sc.gov.br/jsmallfib_top/DHRI/bacias_hidrograficas/bacias_hidrograficas_sc.pdf>. Acesso em: 16 ago. 2018.

SOUZA, A. et al. Similaridade da qualidade das águas superficiais da bacia do Rio Negro, MS. Ciência e Natura, Santa Maria, v. 35, n. 2, p. 176-189, 2013. Disponível em: <https://periodicos.ufsm.br/cienciaenatura/article/view/12571/7982>. Acesso em: 24 jul. 2018.

STANDARD METHODS FOR THE EXAMINATION OF WATER AND WASTEWATER. Multiple-tube fermentation technique for members of the coliform group*, 2012. Disponível em: <http://edgeanalytical.com/wpcontent/uploads/Micro_SM9221.pdf>. Acesso em: 06 abr. 2018.

UNITED STATES ENVIRONMENTAL PROTECTION AGENCY - EPA. Method 351.2, Revision 2.0: Determination of Total Kjeldahl Nitrogen by Semi-Automated Colorimetry. Disponível em:

<https://www.epa.gov/sites/production/files/2015-08/documents/method_351-2_1993.pdf>. Acesso em: 30 abr. 2019.

\section{Contribuições dos autores:}

Rubia Girardi - obtenção dos dados, análise e intepretação de dados, elaboração do manuscrito.

Adilson Pinheiro - direcionamento do trabalho e correções do mesmo.

Pedro Thiago Venzon, colaboração na coleta dos dados, apresentação e discussão dos resultados. 